\title{
First Principles Study on the Electronic Structure and Optical Properties of La Doped YB 6 Crystals
}

\author{
Hongbo TANG ${ }^{1}$, Qiuyue LI ${ }^{1}$, Jian ZHOU $^{1}$, Lihua XIAO $^{2 *}$, Ping PENG ${ }^{3}$ \\ ${ }^{1}$ Key Laboratory of Jiangxi University for Applied Chemistry and Chemical Biology, Yichun University, Yichun 336000, \\ China \\ ${ }^{2}$ School of Materials and Metallurgical Engineering, Guizhou Institute of Technology, Guiyang 550003, China \\ ${ }^{3}$ School of Materials Science and Engineering, Hunan University, Changsha, Hunan 410082, China \\ crossref http://dx.doi.org/10.5755/j02.ms.25006
}

Received 03 January 2020; accepted 17 June 2020

\begin{abstract}
We have investigated the optical properties of $\mathrm{La}(0,0.125,0.250)$ doped $\mathrm{YB}_{6}$ by means of first-principles calculations within the framework of density functional theory. It was found that electronic and optical properties of $\mathrm{YB}_{6} \mathrm{crystals}$ varied remarkably when $\mathrm{Y}$ atoms were replaced with $\mathrm{La}$ atoms. Furthermore, with increasing content of $\mathrm{La}$ in $\mathrm{YB}_{6}$ crystals from $12.5 \%$ to $25 \%$ reflectivity and absorption coefficient of near infrared light decreased obviously, while the transmittance was enhanced.
\end{abstract}

Keywords: $\mathrm{YB}_{6}$, doped, first principles, optical property.

\section{INTRODUCTION}

Over the past decades, the first-principles calculations have been used widely to investigate performance of various materials. Relevant findings [ $1-3]$ have illustrated that the optical properties of these materials could be characterized in terms of dielectric function, reflectivity, absorption and transmittance function, which are mainly related to band structure and electron density. Recently, an increasing attention has been given towards the rare-earth element boride due to interesting structure and optical properties $[4,5]$. Among them, yttrium hexaboride $\left(\mathrm{YB}_{6}\right)$, an extremely hard, refractory and stable rare-earth hexaboride, has been also applied as solar radiation shielding materials in windows for its high optical absorption coefficient in near-infrared (NIR) range (around $1000 \mathrm{~m}$ ) and ultraviolet (UV) range (around $350 \mathrm{~nm}$ ), and high transmittance in visible region. To our knowledge, a lot of researches have been conducted on thermoelectricity [6], super-conductivity [7] and optical performance [8,9] of $\mathrm{YB}_{6}$. Even though electronic structure and optical properties of pure $\mathrm{YB}_{6}$ have been reported by Xiao $[8,9]$, there are no relevant researches on La doped $\mathrm{YB}_{6}$. Yttrium and lanthanum belong to one family; they possess many similarities in structure and physicochemical property. Within this paper, band structure, density of states, dielectric function, refractive index, reflectivity, absorption coefficient and transmittance of $\mathrm{La}$ doped $\mathrm{YB}_{6}$ are analyzed and discussed in detail.

\section{DETAILS OF CALCULATION}

All first-principles calculations were conducted on the basis of density-functional theory incorporated into the Cambridge Serial Total Energy Package (CASTEP) computational code [10]. The interaction between valence

*Corresponding author. Tel.: +86-18275081939.

E-mail address: xiaolihua@git.edu.cn (L. Xiao) electrons and nucleus with positive charges was represented in terms of ultra-soft pseudopotentials [11]. The exchange correlation energy was measured by the generalized gradient approximation (GGA) proposed before $[8,9,12]$. Brillouin zone integration was obtained through the Monkhorst-Pack scheme [13]. Geometry optimization was achieved by convergence thresholds of $2 \times 10^{-5} \mathrm{eV} \AA^{-1}$ for total energy and $0.05 \mathrm{eV}^{-1}$ for maximum force. It is sufficient to adopt the plane wave cut-off energy of $380 \mathrm{eV}$ and a $6 \times 6 \times 6 \mathrm{k}$-point mesh to ensure convergence for the total energy.

In general, $\mathrm{YB}_{6}$ shows a CsCl-type structure with a Pm3m space group (No. 221), in which $\mathrm{Y}$ atom and $\mathrm{B}_{6}$ octahedron take the sites of cesium and chlorine, respectively. Calculations of the La-doped $\mathrm{YB}_{6}$ have been performed within a $2 \times 2 \times 2$ supercell of $\mathrm{La}_{0.125} \mathrm{Y}_{0.875} \mathrm{~B}_{6}$, as presented in Fig. $1 \mathrm{~b}$, and a $2 \times 2 \times 1$ supercell of $\mathrm{La}_{0.250} \mathrm{Y}_{0.750} \mathrm{~B}_{6}$ in Fig. 1.

\section{RESULTS AND DISCUSSION}

\subsection{Structural and electronic properties}

$\mathrm{Y}$ atom occupies the Wyckoff site $1 \alpha(0,0,0)$, and $\mathrm{B}$ atom locates at the $6 f(\mathrm{z}, 0.5,0.5)$ site, with $\mathrm{z}$ acting as an internal parameter. According to the previous experimental research [8], the experimental data of $\alpha=4.051 \AA$ and $\mathrm{z}=0.1991 \AA$ were set as the initial input for geometry optimization. As many experimental findings reported $[8,14]$, optimized lattice constants were $\mathrm{a}=4.052 \AA$ and $\mathrm{z}=0.199 \AA$ for pure $\mathrm{YB}_{6}$.

Fig. 2 shows the calculated total density of states (TDOS) of pure $\mathrm{YB}_{6}, \mathrm{La}_{0.125} \mathrm{Y}_{0.875} \mathrm{~B}_{6}$ and $\mathrm{La}_{0.25} \mathrm{Y}_{0.75} \mathrm{~B}_{6}$, where the Fermi energy level is chosen to be the zero position of the energy scale. As illustrated in the TDOS curves, many bands of two La-doped $\mathrm{YB}_{6}$ samples cross the Fermi energy level, indicating typical conductor behavior. So it can be concluded that they could be used as conductors like $\mathrm{YB}_{6}$. 


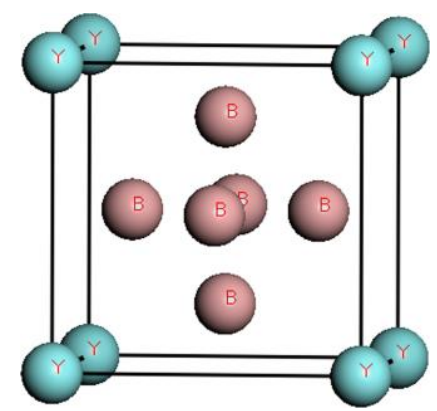

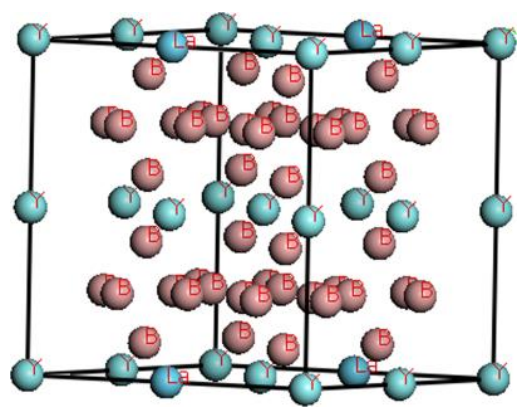

b

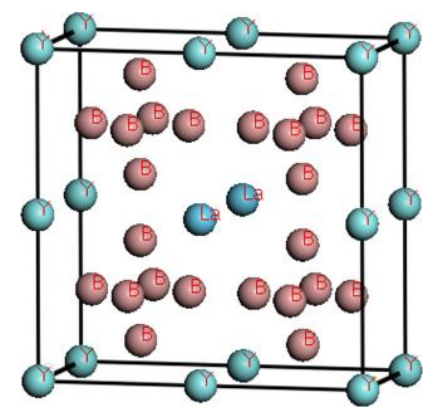

$\mathrm{c}$

Fig. 1. Supercell structure: $a-Y_{6} ; b-L a 0.125 Y_{0.875} B_{6} ; c-L a 0.25 Y_{0.75} B_{6}$

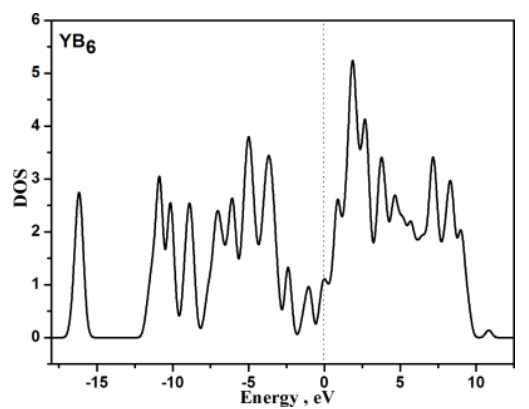

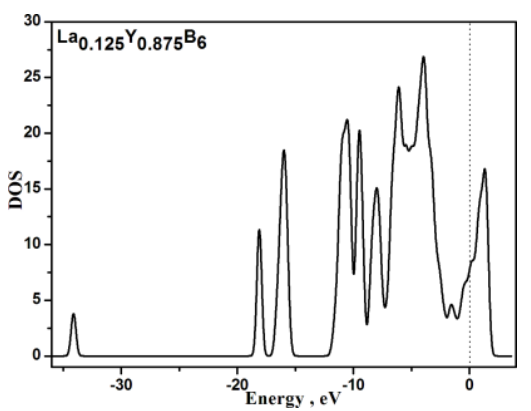

b

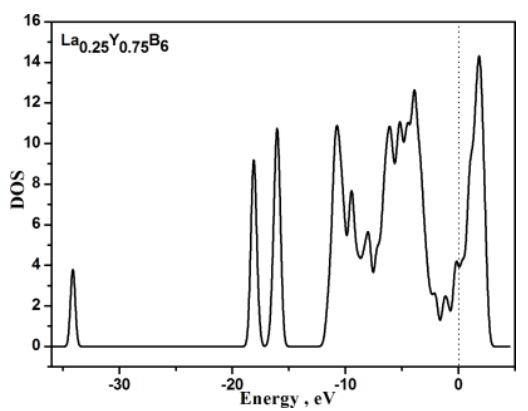

c

Fig. 2. Total density of states: a $-\mathrm{YB}_{6} ; \mathrm{b}-\mathrm{La}_{0.125} \mathrm{Y}_{0.875} \mathrm{~B}_{6} ; \mathrm{c}-\mathrm{La} 0.25 \mathrm{Y}_{0.75} \mathrm{~B}_{6}$

The partial density of states of $\mathrm{YB}_{6}$ was obtained, but it is not present here because it is due to its consistency with what has been reported by Xiao et al. [8]. The band structures of pure $\mathrm{YB}_{6}, \mathrm{La}_{0.125} \mathrm{Y}_{0.875} \mathrm{~B}_{6}$ and $\mathrm{La}_{0.25} \mathrm{Y}_{0.75} \mathrm{~B}_{6}$ are plotted in Fig. 3. It can be noticed that the valence bands of the three samples go across the Fermi energy as well, which indicates that the original $\mathrm{YB}_{6}, \mathrm{La}_{0.125} \mathrm{Y}_{0.875} \mathrm{~B}_{6}$ and $\mathrm{La}_{0.25} \mathrm{Y}_{0.75} \mathrm{~B}_{6}$ possess good electrical conductivity.

The above results demonstrate that the $\mathrm{YB}_{6}$ compounds, no matter pure or doped with low content of the rare-earth element La, show superior conductivity.

\subsection{Optical properties}

\subsubsection{Complex dielectric function}

In this section, the complex dielectric function $\varepsilon(\omega)=\varepsilon_{1}(\omega)+i \varepsilon_{2}(\omega)$ is usually taken to describe the photon excitation of materials. It has a linear correlation with electromagnetic radiation of materials [15]. The real

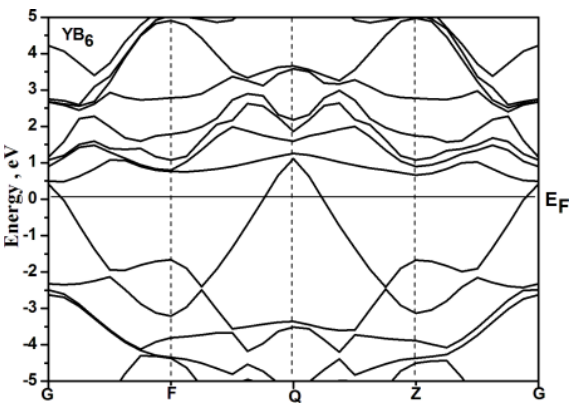

a

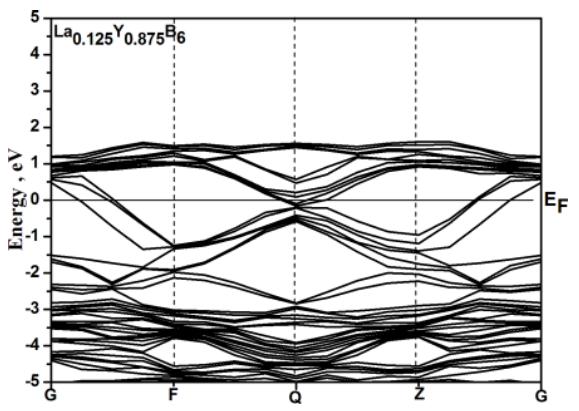

b part $(\mathrm{Re})$ of the dielectric function $\varepsilon_{1}(\omega)$ describes the dipole polarization intensity and the imaginary part (Im) $\varepsilon_{2}(\omega)$ is a key parameter in the optical performance. It is related to the electron excitation between occupied and unoccupied bands. Fig. 4 shows the dielectric function of $\mathrm{YB}_{6}, \mathrm{La}_{0.125} \mathrm{Y}_{0.875} \mathrm{~B}_{6}$ and $\mathrm{La}_{0.25} \mathrm{Y}_{0.75} \mathrm{~B}_{6}$.

It can be observed from the real part that there is a transition from the metallic state to the dielectric state for $\mathrm{YB}_{6}$ and $\mathrm{La}_{0.125} \mathrm{Y}_{0.875} \mathrm{~B}_{6}$, while for $\mathrm{La}_{0.25} \mathrm{Y}_{0.75} \mathrm{~B}_{6}$ no transition zone exists in the curve. The imaginary part of $\mathrm{La}_{0.25} \mathrm{Y}_{0.75} \mathrm{~B}_{6}$ obviously differs from those of the other two sample. This may be ascribed to different electron excitation modes they possess. Thus, it can be concluded that concentration of $\mathrm{La}$ in $\mathrm{YB}_{6}$ has great influence on dielectric function of hexaborides. Then systematical analysis on reflectivity, absorption and transmittance was conducted to compare optical properties of $\mathrm{YB}_{6}$, $\mathrm{La}_{0.125} \mathrm{Y}_{0.875} \mathrm{~B}_{6}$ and $\mathrm{La}_{0.25} \mathrm{Y}_{0.75} \mathrm{~B}_{6}$.

Fig. 3. Energy band structures: $a-\mathrm{YB}_{6} ; \mathrm{b}-\mathrm{La} 0.125 \mathrm{Y}_{0.875} \mathrm{~B}_{6} ; \mathrm{c}-\mathrm{La} 0.25 \mathrm{Y}_{0.75} \mathrm{~B}_{6}$ 

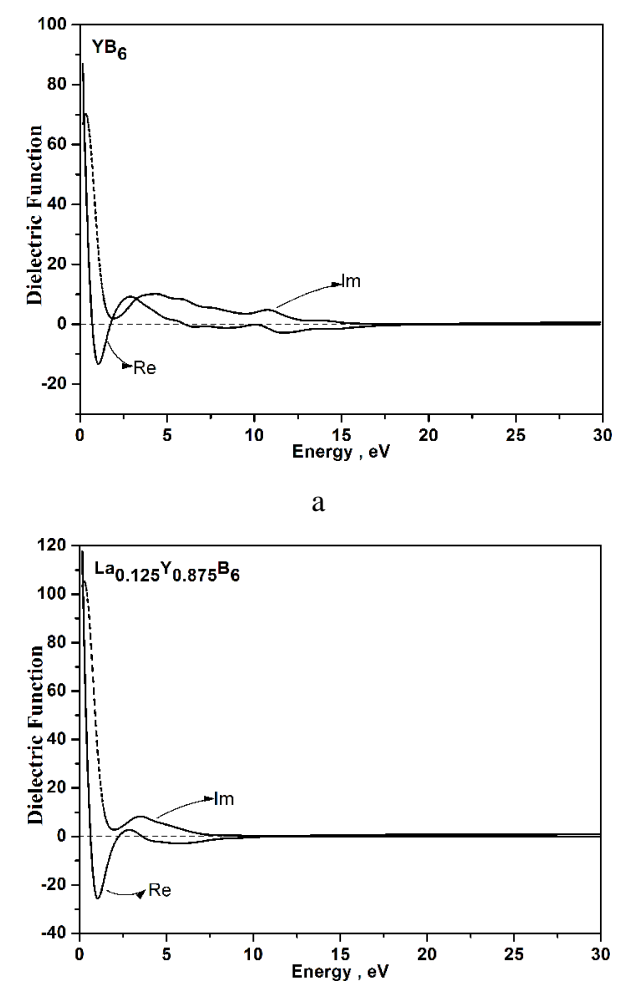

b

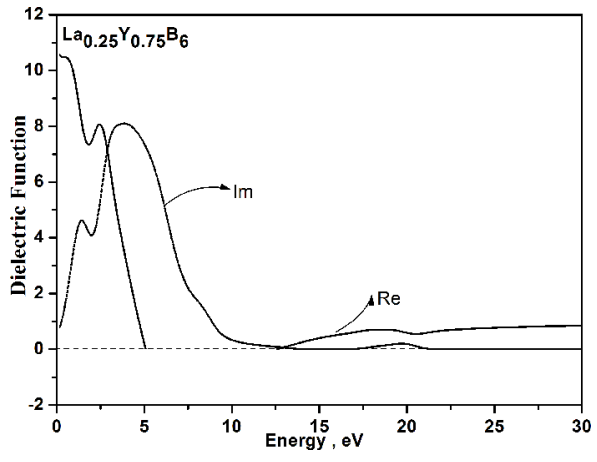

c

Fig. 4. Real part $\left(\varepsilon_{1}\right)$ and imaginary part $\left(\varepsilon_{2}\right)$ of the complex dielectric constant spectra: $\mathrm{a}-\mathrm{YB}_{6} ; \mathrm{b}-\mathrm{La}_{0.125} \mathrm{Y}_{0.875} \mathrm{~B}_{6}$; $\mathrm{c}-\mathrm{La}_{0.25} \mathrm{Y}_{0.75} \mathrm{~B}_{6}$

\subsubsection{Reflectivity spectra}

Fig. 5 depicts the reflectivity spectra of $\mathrm{YB}_{6}$, $\mathrm{La}_{0.125} \mathrm{Y}_{0.875} \mathrm{~B}_{6}$ and $\mathrm{La}_{0.25} \mathrm{Y}_{0.75} \mathrm{~B}_{6}$.

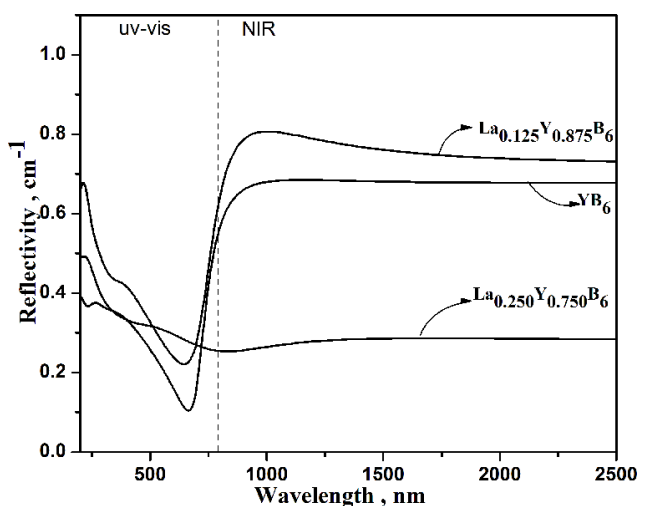

Fig. 5. The reflection spectra of $\mathrm{YB}_{6}, \mathrm{La}_{0.125} \mathrm{Y}_{0.875} \mathrm{~B}_{6}$ and $\mathrm{La}_{0.25} \mathrm{Y}_{0.75} \mathrm{~B}_{6}$
The energy positions of the plasma edge for $\mathrm{YB}_{6}$ and $\mathrm{La}_{0.125} \mathrm{Y}_{0.875} \mathrm{~B}_{6}$ are $\mathrm{V}$ shaped in the visible region, the corresponding minimum values are $695 \mathrm{~nm}$ and $685 \mathrm{~nm}$, respectively. The sample $\mathrm{La}_{0.25} \mathrm{Y}_{0.75} \mathrm{~B}_{6}$ shows a relatively low energy position of the plasma edge in the visible region. It also can be observed in Fig. 5 that the maximum reflectivity for $\mathrm{YB}_{6}, \mathrm{La}_{0.125} \mathrm{Y}_{0.875} \mathrm{~B}_{6}$ and $\mathrm{La}_{0.25} \mathrm{Y}_{0.75} \mathrm{~B}_{6}$ in the near infrared region (NIR) is $70 \%, 80 \%$ and $28 \%$, respectively. It demonstrates that reflectivity of this kind of materials can be regulated by changing concentration of La.

\subsubsection{Absorption spectrum}

It can be observed from the absorption spectra of $\mathrm{YB}_{6}$, $\mathrm{La}_{0.125} \mathrm{Y}_{0.875} \mathrm{~B}_{6}$ and $\mathrm{La}_{0.25} \mathrm{Y}_{0.75} \mathrm{~B}_{6}$ in Fig. 6 that each curve shows a strong absorption peak in the UV region and relatively weak absorption peak in the visible region. Especially for $\mathrm{La}_{0.25} \mathrm{Y}_{0.75} \mathrm{~B}_{6}$ the peak in visible region is far too subtle to be noticed. As observed from the absorption curves of $\mathrm{YB}_{6}$, a clear absorption valley appears at around $600 \mathrm{~nm}$ and there is an absorption peak at around $1100 \mathrm{~nm}$ in NIR region. Interestingly, when the La doping content goes up to $12.5 \%$, the absorption valley shifts toward a higher wavelength. With further increasing the content to $25 \%$, the corresponding curve is much different from the others. The spectrum shows an absorption peak at visible light region, and then the data changes abruptly and decreases to a minimum value till $2500 \mathrm{~nm}$. As we all know, the position of the absorption valley is always accompanied by the maximum transmission of light. So it can be deduced from this theoretical results that these materials can filter various wavelengths of light from the visible region by tailoring the component.

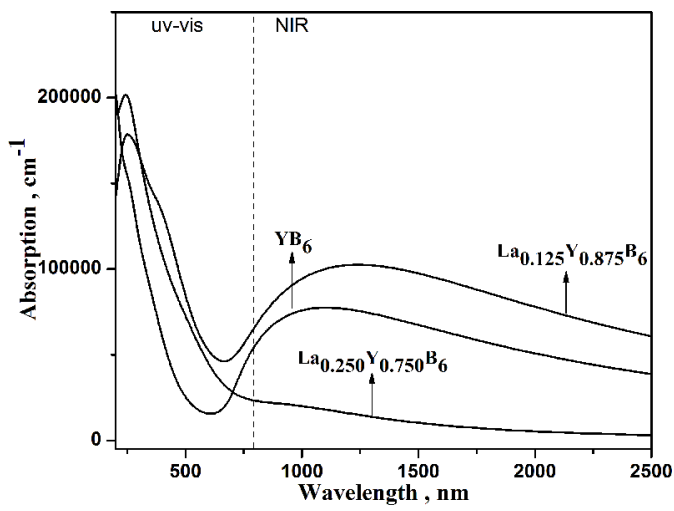

Fig. 6. The absorption spectra of $\mathrm{YB}_{6}, \mathrm{La}_{0.125} \mathrm{Y}_{0.875} \mathrm{~B}_{6}$ and $\mathrm{La}_{0.25} \mathrm{Y}_{0.75} \mathrm{~B}_{6}$

\subsubsection{Theoretical transmittance}

The theoretical transmittance of $\mathrm{YB}_{6}, \mathrm{La}_{0.125} \mathrm{Y}_{0.875} \mathrm{~B}_{6}$ and $\mathrm{La}_{0.25} \mathrm{Y}_{0.75} \mathrm{~B}_{6}$ films can be obtained according to the Eq. 1 [9]:

$T=\frac{\left(1-R^{2}\right) \exp (-\alpha d)}{1-R^{2} \exp (-2 \alpha d)}$

where $T$ is the theoretical transmittance; $R$ is the reflectivity; $\alpha$ is the absorption coefficient; $d$ is the film thickness. Fig. 7 presents theoretical transmittance of a $50 \mathrm{~nm}$ thick film of these samples in the UV-Vis-NIR range. The theoretical transmittance is originated from the 
reflection spectrum (Fig. 5) and absorption spectra (Fig. 6) of the samples. It demonstrates that calculated theoretical transmittance values of the compacted films of $\mathrm{YB}_{6}$, $\mathrm{La}_{0.125} \mathrm{Y}_{0.875} \mathrm{~B}_{6}$ and $\mathrm{La}_{0.25} \mathrm{Y}_{0.75} \mathrm{~B}_{6}$ are different.

Moreover, it can be observed in Fig. 7 that in UV-Vis region, $\mathrm{YB}_{6}$ and $\mathrm{La}_{0.125} \mathrm{Y}_{0.875} \mathrm{~B}_{6}$ films show transmittance peak at around $695 \mathrm{~nm}$ and $685 \mathrm{~nm}$, respectively, but in NIR region they both present weak transmittance. On the contrary, $\mathrm{La}_{0.25} \mathrm{Y}_{0.75} \mathrm{~B}_{6}$ displays high transmittance in the UV-Vis and NIR regions. That is, the transmittance of the La-doped samples in NIR region increases from around $10 \%$ to $50 \%$ apparently by adjusting the content of $\mathrm{La}$ from $12.5 \%$ to $25 \%$.

Based on the above findings, it is found that both $\mathrm{YB}_{6}$ and $\mathrm{La}_{0.125} \mathrm{Y}_{0.875} \mathrm{~B}_{6}$ are promising solar radiation shielding materials for windows, which require high transmittance for visible light and high blocking effect for near infrared waves [8], while $\mathrm{La}_{0.25} \mathrm{Y}_{0.75} \mathrm{~B}_{6}$ might serve as filter materials. Obviously, the optical tunable characteristic of the ternary materials shows greater potential in practical application than the binary $\mathrm{YB}_{6}$.

Meanwhile, we noticed some interesting theoretical results, such as similarity in electronic structures and optical properties of $\mathrm{YB}_{6}$ and $\mathrm{La}_{0.125} \mathrm{Y}_{0.875} \mathrm{~B}_{6}$, and an abrupt leap in the performance when the La content increased to $25 \%$. These are supposed to be researched and discussed in our future work.

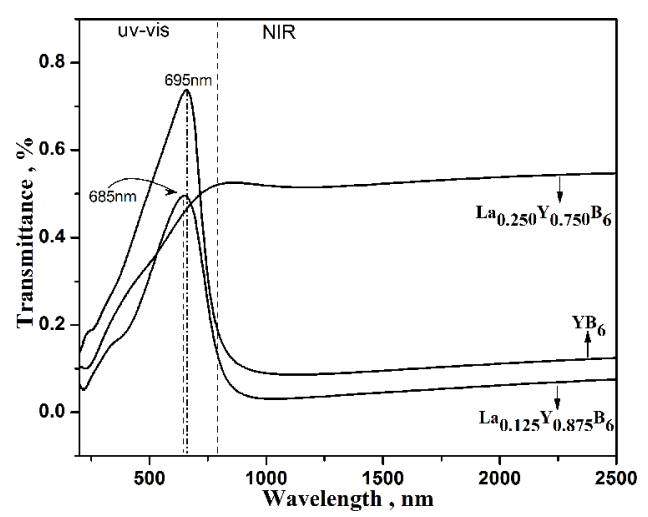

Fig. 7. Theoretical transmittance of $50 \mathrm{~nm}$ thick films of $\mathrm{YB}_{6}$, $\mathrm{La}_{0.125} \mathrm{Y}_{0.875} \mathrm{~B}_{6}$ and $\mathrm{La}_{0.25} \mathrm{Y}_{0.75} \mathrm{~B}_{6}$

\section{CONCLUSIONS}

In summary, electronic structure and optical characteristics of $\mathrm{YB}_{6}, \mathrm{La}_{0.125} \mathrm{Y}_{0.875} \mathrm{~B}_{6}$ and $\mathrm{La}_{0.25} \mathrm{Y}_{0.75} \mathrm{~B}_{6}$ have been calculated by the density-functional theory within the GGA. The as-obtained lattice constant and optical parameters are in good consistency with reported experimental results. Our findings show that $\mathrm{YB}_{6}$ and $\mathrm{La}_{0.125} \mathrm{Y}_{0.875} \mathrm{~B}_{6}$ are ideal for the near-infrared absorption/reflectance materials and solar radiation shielding materials for windows which require high transmittance of visible light. As for the $\mathrm{La}_{0.25} \mathrm{Y}_{0.75} \mathrm{~B}_{6}$, it may find potential application in filter materials due to its low absorption/reflectance and high transmittance in NIR.

\section{Acknowledgments}

This work is financially supported by the National Natural Science Foundation of China (Nos. 51776046,
61751501), the Foundation of Jiangxi Provincial Education Department (Grant Nos. GJJ161022 and GJJ161035), the Science and Technology Project of Guizhou Province ([2019]1133) and Youth Science and Technology Talent Development Fund in Guizhou Provincial Department of Education ([2018]250).

\section{REFERENCES}

1. Rohlfing, M., Louie, S.G. Electron-hole Excitations and Optical Spectra from First Principles Physical Review B 62 (8) 2000: pp. 4927-4944. https://doi.org/10.1103/PhysRevB.62.4927

2. Norman, P., Agren, H. First-Principle Quantum Modeling of Optical Power Limiting Materials Journal of Computational and Theoretical Nanoscience 1 (4) 2004: pp. 343-366. https://doi.org/10.1166/jctn.2004.034

3. Brik, M.G., Mahlik, S., Jankowski, D., Strak, P., Korona, K.P., Monroy, E., Krukowski, S., Kaminska, A. Experimental and First-Principles Studies of High-Pressure Effects on the Structural, Electronic, and Optical Properties of Semiconductors and Lanthanide Doped Solids Japanese Journal of Applied Physics 56 (5) 2017: pp. 05FA02. https://doi.org/10.7567/JJAP.56.05FA02

4. Yuan, Y.F., Zhang, L., Hu, L.J., Wang, W., Min, G.H. Size Effect of Added $\mathrm{LaB}_{6}$ Particles on Optical Properties of $\mathrm{LaB}_{6} /$ Polymer Composites Journal of Solid State Chemistry 184 (12) 2011: pp. $3364-3367$. https://doi.org/10.1016/j.jssc.2011.10.036

5. Tang, H.B., Su, Y.C., Hu, T., Liu, S.D., Mu, S.J., Xiao, L.H. Synergetic Effect of $\mathrm{LaB}_{6}$ and ITO Nanoparticles on Optical Properties and Thermal Stability of Poly(vinylbutyral) Nanocomposite Films Applied Physics A-Materials Science \& Processing 117 (4) 2014: pp. 2127-2132. https://doi.org/10.1007/s00339-014-8632-8

6. Lortz, R., Wang, Y., Tutsch, U., Abe, S., Meingast, C., Popovich, P., Knafo, W., Shitsevalova, N., Paderno, Y.B., Junod, A. Superconductivity Mediated by a Soft Phonon Mode: Specific Heat, Resistivity, Thermal Expansion, and Magnetization of $\mathrm{YB}_{6}$ Physical Review B 73 (2) 2006: pp. 024512. https://doi.org/10.1103/PhysRevB.73.024512

7. Szabo, P., Girovsky, J., Pribulova, Z., Kacmarcik, J., Mori, T., Samuely, P. Point-contact Spectroscopy of the Phononic Mechanism of Superconductivity in $\mathrm{YB}_{6}$ Superconductor Science \& Technology 26 (4) 2013: pp. 045019. https://doi.org/10.1088/0953-2048/26/4/045019

8. Xiao, L.H., Su, Y.C., Chen, H.Y., Jiang, M., Liu, S.N., Hu, Z.X., Liu, R.F., Peng, P., Mu, Y.L., Zhu, D.Y. Study on the Electronic Structure and the Optical Performance of $\mathrm{YB}_{6}$ by the First-Principles Calculations AIP Advances 1 (2) 2014: pp. 022140. https://doi.org/10.1063/1.3602854

9. Xiao, L.H., Su, Y.C., Zhou, X.Z., Chen, H.Y., Tan, J., Hu, T., Yan, J., Peng, P. Origins of High Visible Light Transparency and Solar Heat-Shielding Performance in LaB 6 Applied Physics Letters 101 (4) 2012: pp. 041913. https://doi.org/10.1063/1.4733386

10. Segall, M.D., $\quad$ Lindan, P.J.D., $\quad$ Probert, M.J., Pickard, C.J., Hasnip, P.J., Clark, S.J., Payne, M.C. First-Principles Simulation: Ideas, Illustrations and the 
CASTEP Code Journal of Physics-Condensed Matter 14 (11) 2002: pp. $2717-2744$.

https://doi.org/10.1088/0953-8984/14/11/301

11. John P.P., Kieron B., Wang Y. Generalized Gradient Approximation for the Exchange-Correlation Hole of a Many-Electron System Physical Review B, Condensed Matter 54 (23) 1996: pp. 16533 - 16539.

https://doi.org/10.1103/PhysRevB.54.16533

12. Diedrich, C., Grimme, S. Systematic Investigation of Modern Quantum Chemical Methods to Predict Electronic Circular Dichroism Spectra Journal of Physical Chemistry A 107 (14) 2003: pp. 2524-2539. https://doi.org/10.1021/jp0275802

13. Yang, X.P., Chen, J.W., Jiang, H., Dong, J.M. Chiral Symmetry of Double-Walled Carbon Nanotubes Detected in
First-Principles Optical Absorption Spectra Review B 69 (19) 2004: pp. 193401 https://doi.org/10.1103/PhysRevB.69.193401

14. Ning, G.R., Flemming, R.L. Rietveld Refinement of LaB6: Data from Mu XRD Journal of Applied Crystallography 38 (5) 2005: pp. $757-759$. https://doi.org/10.1107/S0021889805023344

15. Xu, Y., Zhang, L.J., Cui, T., Li, Y., Xie, Y., Yu, W., Ma, Y.M., Zou, G.T. First-Principles Study of the Lattice Dynamics, Thermodynamic Properties and Electron-Phonon Coupling of $\mathrm{YB}_{6}$ Physical Review $B \quad 76$ (21) 2007: pp. 214103. https://doi.org/10.1103/PhysRevB.76.214103

(C) Tang et al. 2022 Open Access This article is distributed under the terms of the Creative Commons Attribution 4.0 International License (http://creativecommons.org/licenses/by/4.0/), which permits unrestricted use, distribution, and reproduction in any medium, provided you give appropriate credit to the original author(s) and the source, provide a link to the Creative Commons license, and indicate if changes were made. 